\title{
1 Changing seasonality of moderate and extreme precipitation events in the Alps
}

2 Stefan Brönnimann ${ }^{1,2}$, Jan Rajczak ${ }^{3}$, Erich Fischer ${ }^{3}$, Christoph C. Raible ${ }^{1,4}$, Marco Rohrer ${ }^{1,2}$, Christoph

3 Schär ${ }^{3}$

4

$5 \quad{ }^{1}$ Oeschger Centre for Climate Change Research, University of Bern, Switzerland

$6 \quad{ }^{2}$ Institute of Geography, University of Bern, Switzerland

$7 \quad{ }^{3}$ Institute for Atmospheric and Climate Science, ETH Zurich, Switzerland

$8 \quad{ }^{4}$ Climate and Environmental Physics, Physics Institute, University of Bern, Switzerland

\section{Supplementary Material}

Table S1: COREDX model simulations and modeling groups (CLMcom - CLM Community, HMS Hungarian Meteorological Service, ICTP - International Centre for Theoretical Physics, ICHE - Irish Centre for High-End Computing, MPI - Max Planck Institute for Meteorology, SMHI - Swedish Meteorological and Hydrological Institute, KNMI - Royal Netherlands Meteorological Institute, IPSL - Institut Pierre-Simon-Laplace, DMI - Danish Meteorological Institute, CNRM - National Centre for Meteorological Research, MOHC - UK Met Office, Hadley Center).

\begin{tabular}{|c|c|c|c|}
\hline Ensemble & Regional Model & Global Model & Member \\
\hline \multirow{15}{*}{$\begin{array}{l}\text { CORDEX11, } \\
\text { RCP8.5 }\end{array}$} & CLMcom.CCLM4.8.17 & CNRM.CERFACS.CNRM.CM5 & r1i1p1 \\
\hline & CLMcom.CCLM4.8.17 & ICHEC.EC.EARTH & $\mathrm{r} 12 \mathrm{i} 1 \mathrm{p} 1$ \\
\hline & CLMcom.CCLM4.8.17 & MOHC.HadGEM2.ES & rli1p1 \\
\hline & CLMcom.CCLM4.8.17 & MPI.M.MPI.ESM.LR & rlilp1 \\
\hline & CNRM.ALADIN53 & CNRM.CERFACS.CNRM.CM5 & r1ilp1 \\
\hline & DMI.HIRHAM5 & ICHEC.EC.EARTH & r3ilpl \\
\hline & IPSL.INERIS.WRF331F & IPSL.IPSL.CM5A.MR & rlilp1 \\
\hline & KNMI.RACMO22E & ICHEC.EC.EARTH & r1ilp1 \\
\hline & MPI.CSC.REMO2009 & MPI.M.MPI.ESM.LR & rlilpl \\
\hline & MPI.CSC.REMO2009 & MPI.M.MPI.ESM.LR & r2ilp1 \\
\hline & SMHI.RCA4 & CNRM.CERFACS.CNRM.CM5 & rlilp1 \\
\hline & SMHI.RCA4 & ICHEC.EC.EARTH & r12i1p1 \\
\hline & SMHI.RCA4 & IPSL.IPSL.CM5A.MR & rli1p1 \\
\hline & SMHI.RCA4 & MOHC.HadGEM2.ES & rlilp1 \\
\hline & SMHI.RCA4 & MPI.M.MPI.ESM.LR & rli1p1 \\
\hline \multirow{14}{*}{$\begin{array}{l}\text { CORDEX44, } \\
\text { RCP8.5 }\end{array}$} & CLMcom.CCLM4.8.17 & MPI.M.MPI.ESM.LR & rlilpl \\
\hline & CNRM.ALADIN53 & CNRM.CERFACS.CNRM.CM5 & rlilp1 \\
\hline & DMI.HIRHAM5 & ICHEC.EC.EARTH & r3ilp1 \\
\hline & HMS.ALADIN52 & CNRM.CERFACS.CNRM.CM5 & rlilp1 \\
\hline & ICTP.RegCM4.3 & MOHC.HadGEM2.ES & rlilp1 \\
\hline & IPSL.INERIS.WRF331F & IPSL.IPSL.CM5A.MR & rlilp1 \\
\hline & KNMI.RACMO22E & ICHEC.EC.EARTH & rlilp1 \\
\hline & MPI.CSC.REMO2009 & MPI.M.MPI.ESM.LR & rli1p1 \\
\hline & MPI.CSC.REMO2009 & MPI.M.MPI.ESM.LR & r2ilp1 \\
\hline & SMHI.RCA4 & CCCma.CanESM2 & rlilpl \\
\hline & SMHI.RCA4 & CNRM.CERFACS.CNRM.CM5 & rli1p1 \\
\hline & SMHI.RCA4 & CSIRO.QCCCE.CSIRO.Mk3.6.0 & rlilp1 \\
\hline & SMHI.RCA4 & ICHEC.EC.EARTH & r12ilp1 \\
\hline & SMHI.RCA4 & IPSL.IPSL.CM5A.MR & r12i1p1 \\
\hline
\end{tabular}




\begin{tabular}{|c|c|c|c|}
\hline & SMHI.RCA4 & MIROC.MIROC5 & rlilp1 \\
\hline & SMHI.RCA4 & MOHC.HadGEM2.ES & rli1p1 \\
\hline & SMHI.RCA4 & MPI.M.MPI.ESM.LR & r1ilp1 \\
\hline & SMHI.RCA4 & NCC.NorESM1.M & rlilp1 \\
\hline & SMHI.RCA4 & NOAA.GFDL.GFDL.ESM2M & rli1p1 \\
\hline \multirow{15}{*}{$\begin{array}{l}\text { CORDEX11, } \\
\text { RCP4.5 }\end{array}$} & CLMcom.CCLM4.8.17 & CNRM.CERFACS.CNRM.CM5 & r1ilp1 \\
\hline & CLMcom.CCLM4.8.17 & ICHEC.EC.EARTH & r12i1p1 \\
\hline & CLMcom.CCLM4.8.17 & MOHC.HadGEM2.ES & rlilp1 \\
\hline & CLMcom.CCLM4.8.17 & MPI.M.MPI.ESM.LR & rlilp1 \\
\hline & CNRM.ALADIN53 & CNRM.CERFACS.CNRM.CM5 & rli1p1 \\
\hline & DMI.HIRHAM5 & ICHEC.EC.EARTH & r3ilp1 \\
\hline & IPSL.INERIS.WRF331F & IPSL.IPSL.CM5A.MR & rlilp1 \\
\hline & KNMI.RACMO22E & ICHEC.EC.EARTH & rlilp1 \\
\hline & MPI.CSC.REMO2009 & MPI.M.MPI.ESM.LR & rlilp1 \\
\hline & MPI.CSC.REMO2009 & MPI.M.MPI.ESM.LR & r2ilp1 \\
\hline & SMHI.RCA4 & CNRM.CERFACS.CNRM.CM5 & r1i1p1 \\
\hline & SMHI.RCA4 & ICHEC.EC.EARTH & r12ilp1 \\
\hline & SMHI.RCA4 & IPSL.IPSL.CM5A.MR & rli1p1 \\
\hline & SMHI.RCA4 & MOHC.HadGEM2.ES & r1ilp1 \\
\hline & SMHI.RCA4 & MPI.M.MPI.ESM.LR & r1ilp1 \\
\hline \multirow{17}{*}{$\begin{array}{l}\text { CORDEX44, } \\
\text { RCP4.5 }\end{array}$} & CLMcom.CCLM4.8.17 & MPI.M.MPI.ESM.LR & rlilp1 \\
\hline & CNRM.ALADIN53 & CNRM.CERFACS.CNRM.CM5 & rlilp1 \\
\hline & DMI.HIRHAM5 & ICHEC.EC.EARTH & r3i1p1 \\
\hline & IPSL.INERIS.WRF331F & IPSL.IPSL.CM5A.MR & r1ilp1 \\
\hline & KNMI.RACMO22E & ICHEC.EC.EARTH & rlilpl \\
\hline & MPI.CSC.REMO2009 & MPI.M.MPI.ESM.LR & rlilp1 \\
\hline & MPI.CSC.REMO2009 & MPI.M.MPI.ESM.LR & r2ilp1 \\
\hline & SMHI.RCA4 & CCCma.CanESM2 & rlilp1 \\
\hline & SMHI.RCA4 & CNRM.CERFACS.CNRM.CM5 & rlilp1 \\
\hline & SMHI.RCA4 & CSIRO.QCCCE.CSIRO.Mk3.6.0 & r1ilp1 \\
\hline & SMHI.RCA4 & ICHEC.EC.EARTH & r12i1p1 \\
\hline & SMHI.RCA4 & IPSL.IPSL.CM5A.MR & r12ilp1 \\
\hline & SMHI.RCA4 & MIROC.MIROC5 & rlilp1 \\
\hline & SMHI.RCA4 & MOHC.HadGEM2.ES & rlilp1 \\
\hline & SMHI.RCA4 & MPI.M.MPI.ESM.LR & rlilp1 \\
\hline & SMHI.RCA4 & NCC.NorESM1.M & rlilp1 \\
\hline & SMHI.RCA4 & NOAA.GFDL.GFDL.ESM2M & rlilp1 \\
\hline
\end{tabular}


Annual mean temperature, $1900-2014$

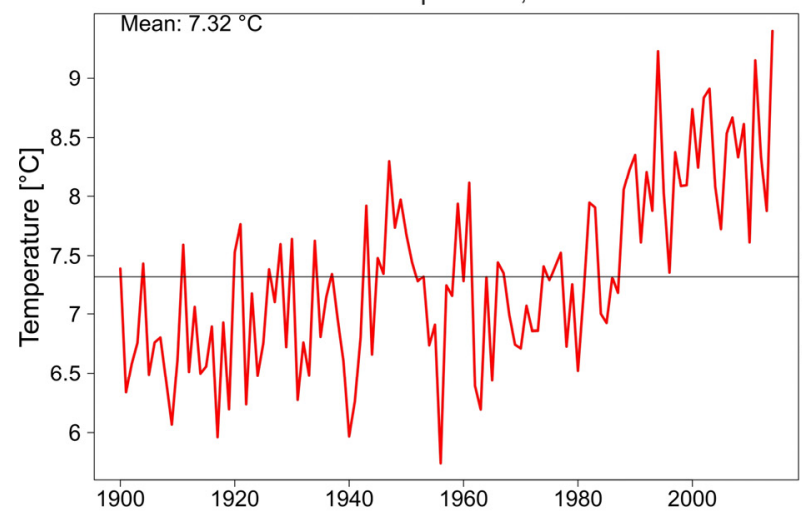

Annual 99-Percentile of Precipitation

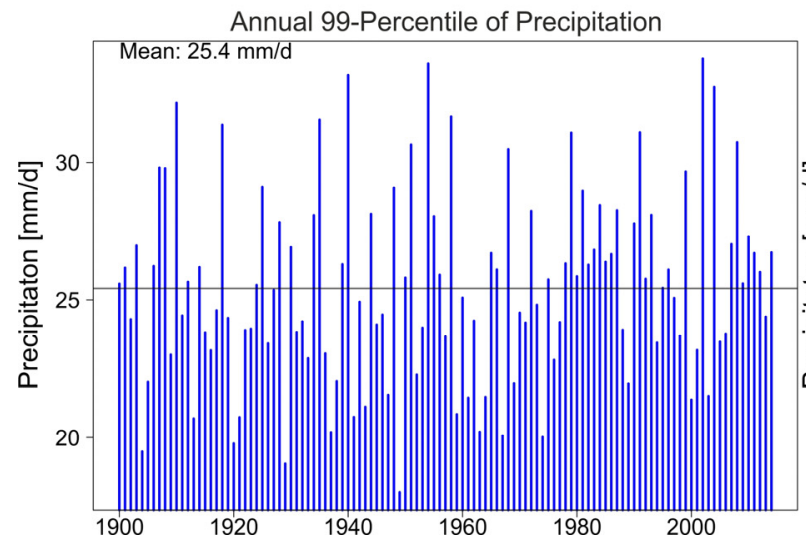

Annual mean precipitation, $1900-2014$

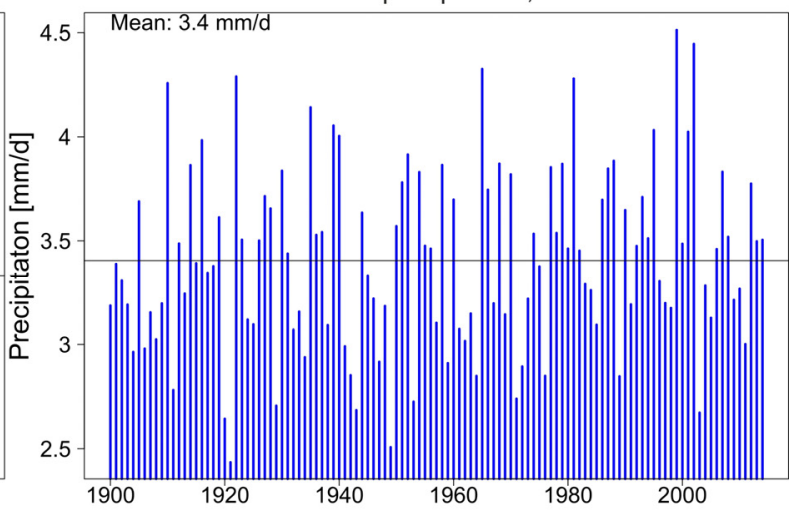

Rx1day

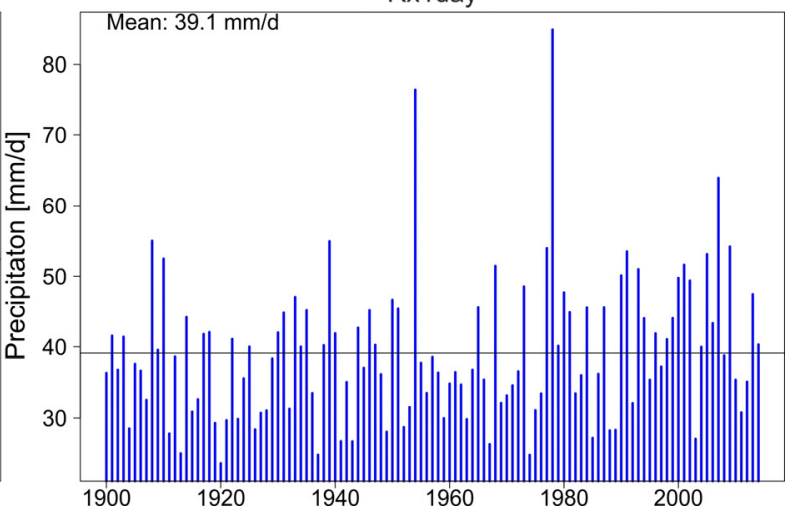

Fig. S1: Catchment-averaged temperature and precipitation statistics based on the average of the stations shown in Fig. 1. Shown are mean temperature, mean precipitation, the annual $99^{\text {th }}$ percentile of precipitation and Rx1day for the period 1900-2014. 

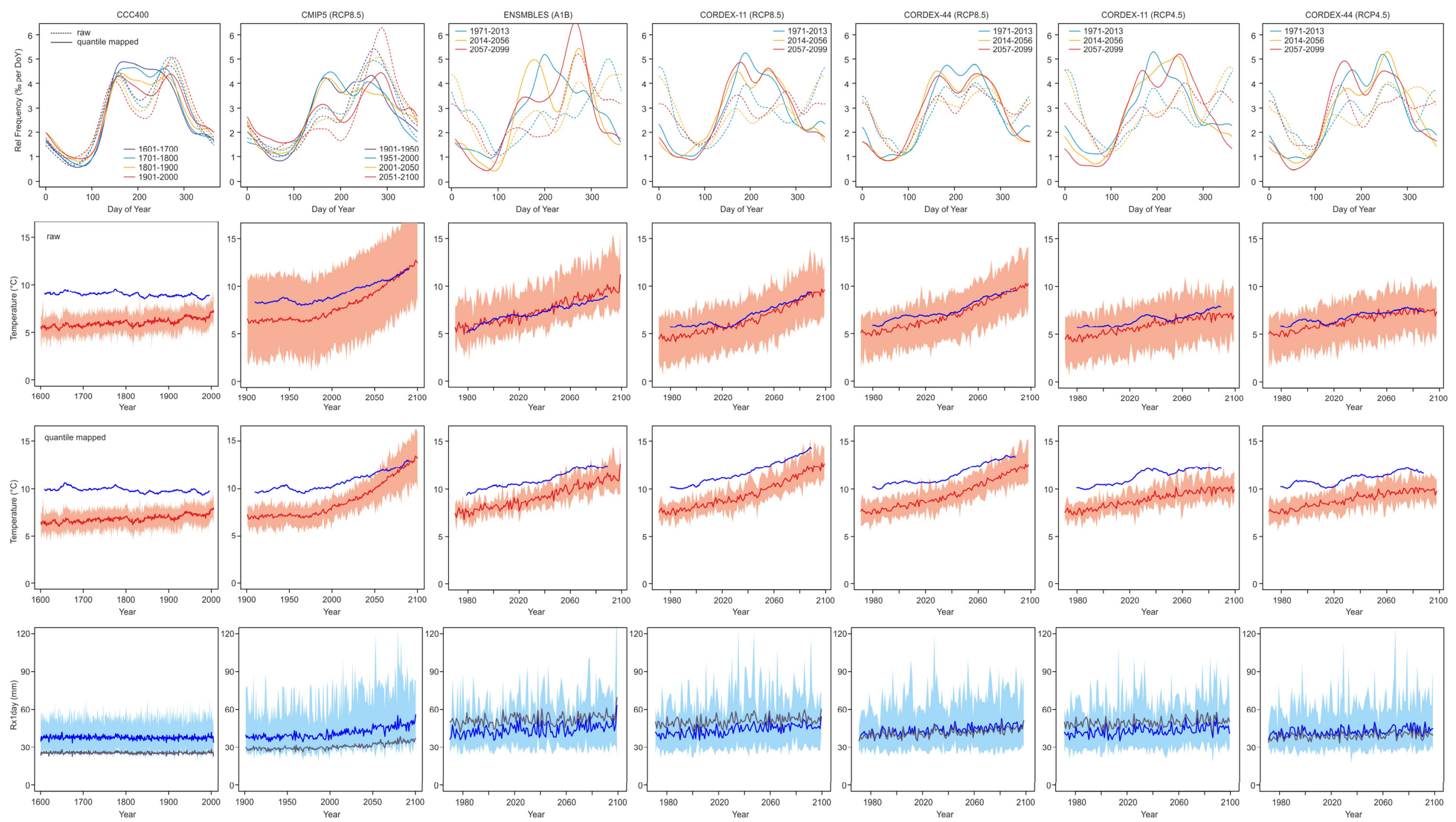

23 Fig. S2: Difference between raw and quantile mapped data for CCC400, CMIP5, ENSEMBLES, CORDEX-11 and CORDEX44 (both RCP4.5 and RCP8.5). (from top to bottom) Top: Day of occurrence of Rx1day for different periods, annual mean temperature and temperature during Rx1day events, and Rx1day (ensemble mean as line and ensemble range as shading; grey line in bottom row indicates the raw data). 


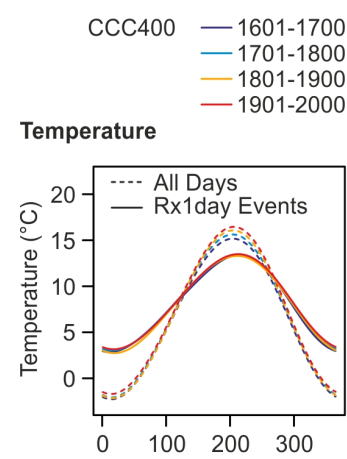

Day of Year

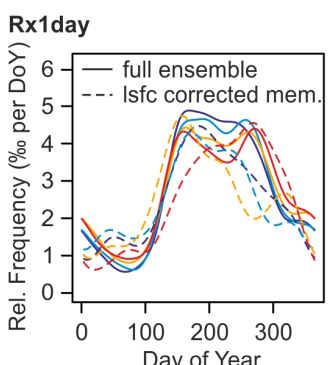

Day of Year

10-yr max. of Rx1day

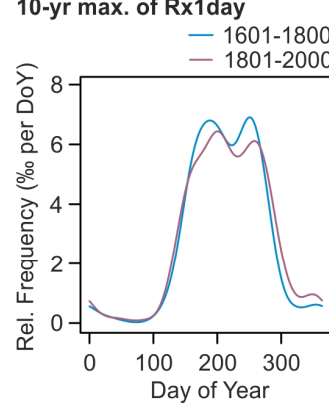

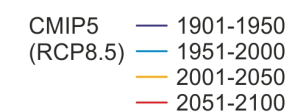

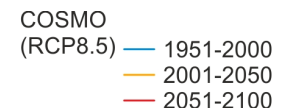
ENSEMBLES
(A1B) - 1970-2013
$-2014-2056$
$-2057-2099$

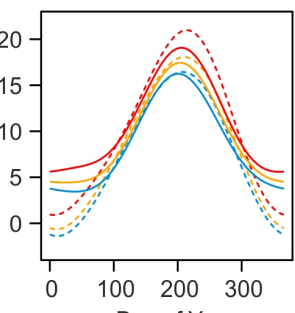

Day of Year

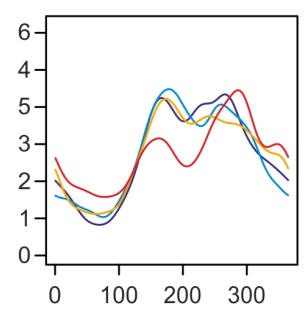

Day of Year
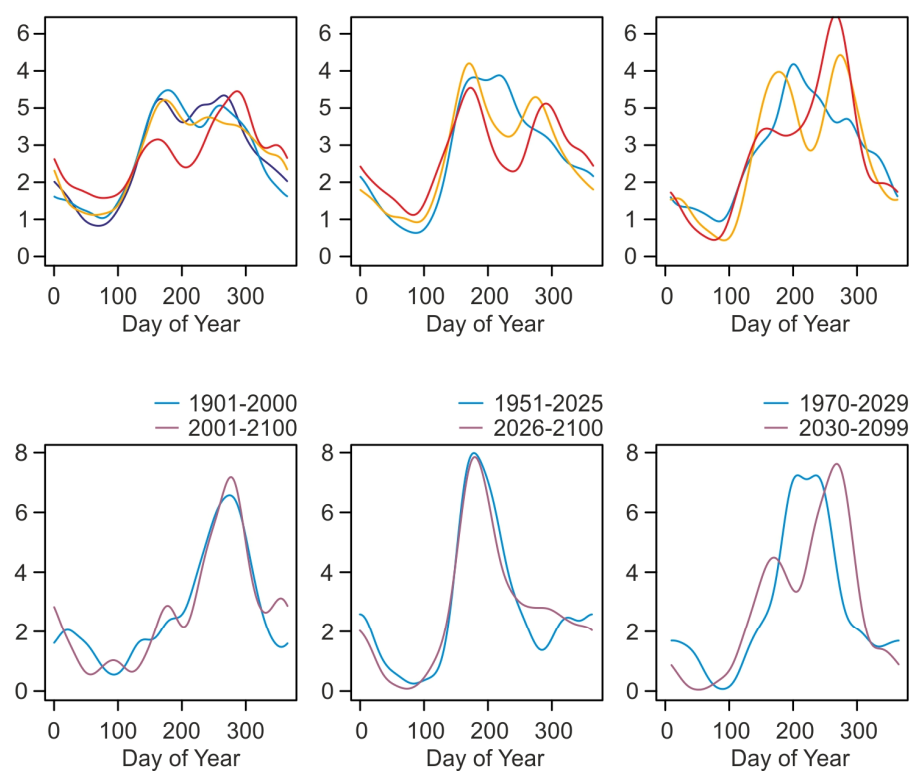

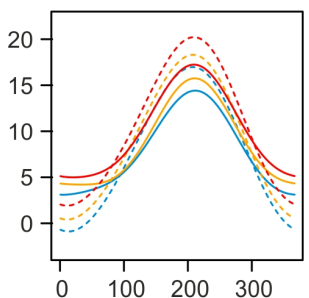

Day of Year

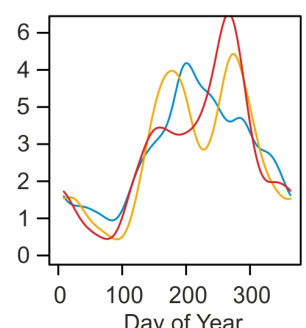

CORDEX-11
(RCP8.5) - 1970-2013 $-2014-2056$
$-2057-2099$

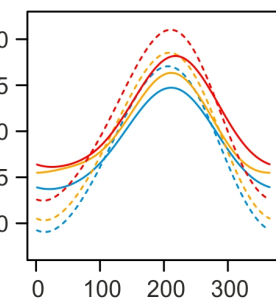

Day of Yea

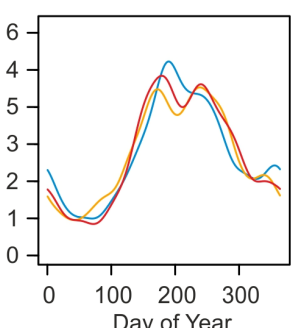

Day of Year
CORDEX-44
(RCP8.5) - 1970-2013 $-2014-2056$
$-2057-2099$

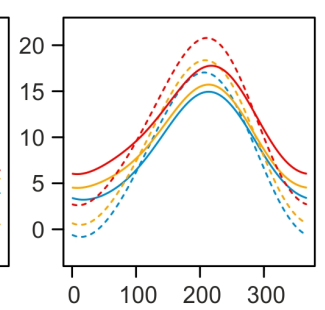

Day of Year
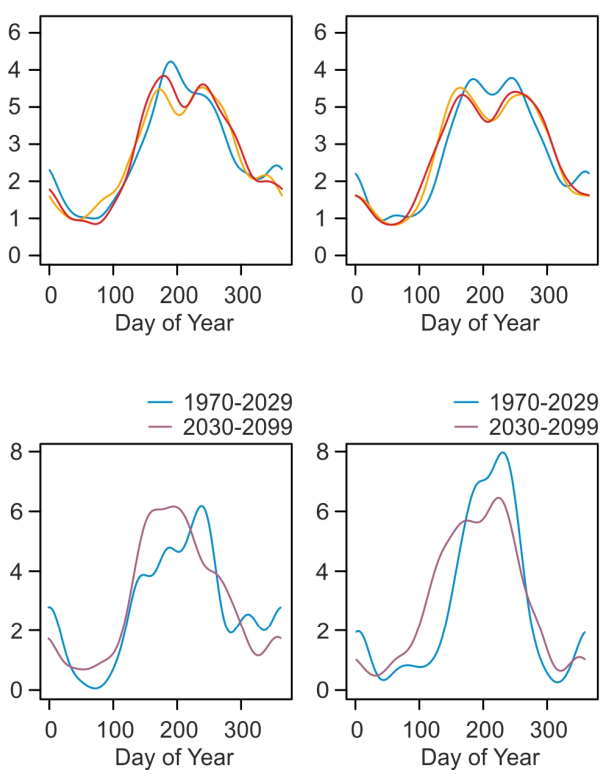
CORDEX-11
(RCP45) - 1970-2013
$-2014-2056$
$-2057-2099$

CORDEX-44

(RCP4.5) - 1970-2013 $-2014-2056$
$-2057-2099$

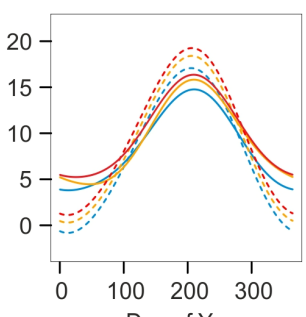

Day of Year

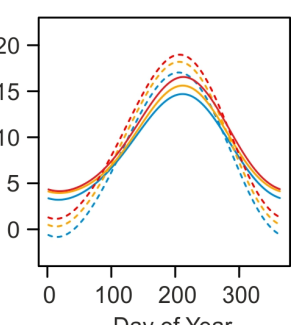

Day of Year

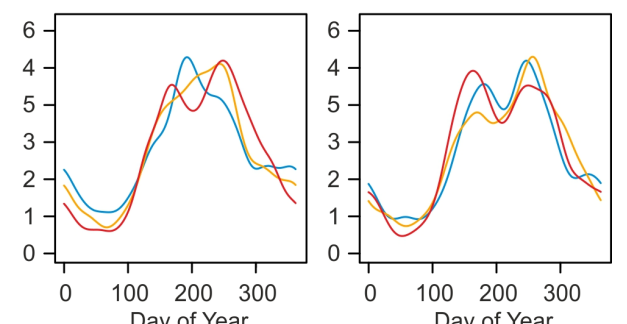

Day of Year

Day of Year

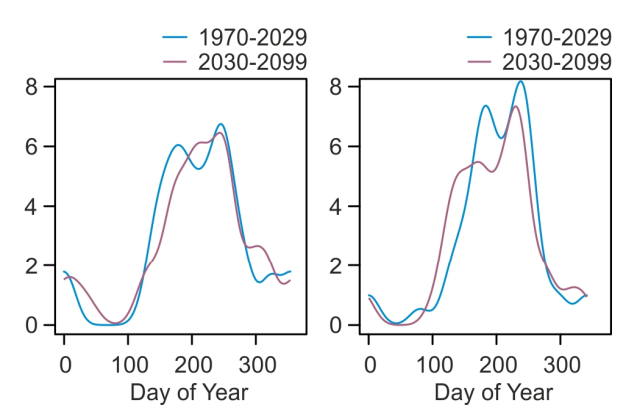

Fig. S3: (top row) Annual mean temperature for all days and for Rx1day (obtained by fitting the first two harmonics of the annual cycle) for the CCC400, CMIP5

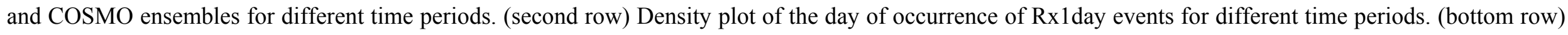

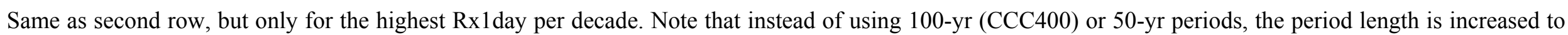

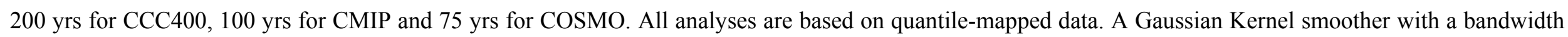

31 of 15 days was used for plotting. For CCC400 we also show a density plot for single member with corrected land surface (with a bandwidth of 25 days). 

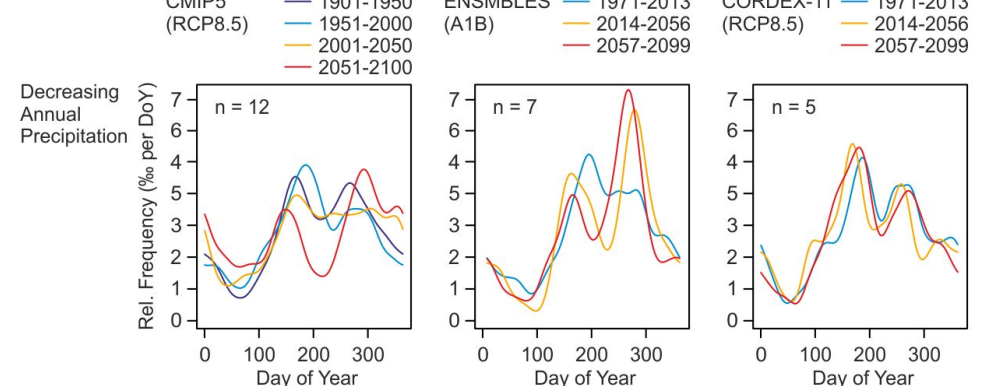

CORDEX-44 - 1971-2013

CORDEX-11 - 1971-2013

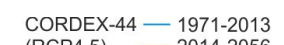

$100 \quad 200 \quad 300$
Day of Year
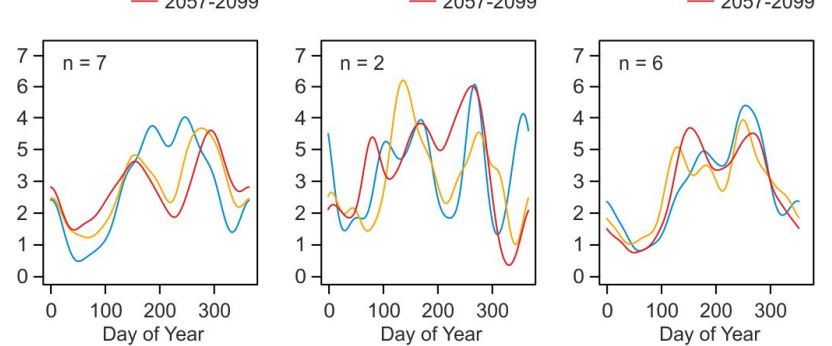

Increasing
Annual
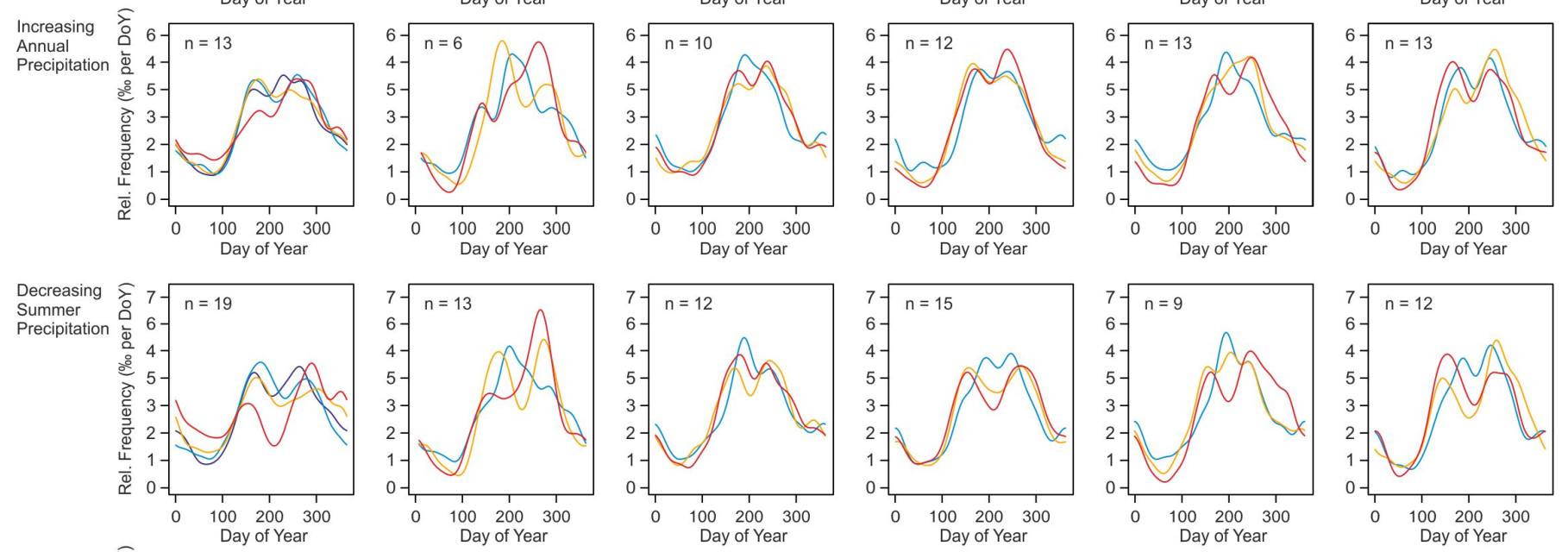

Increasing
Summer
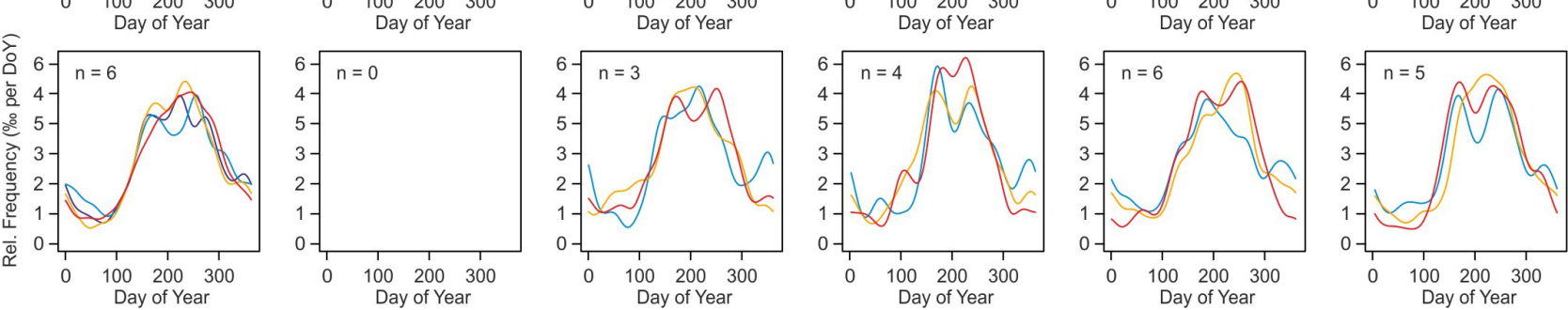

Fig. S4: Density plot of the day of occurrence of Rx1day for different time periods in the multi-model ensembles CMIP5 (same periods as in Fig. S3) as well as in ENSEMBLES, CORDEX-11, and CORDEX-44 (each split into three subperiods). The ensemble members are separated into those that show a positive or negative trend in annual mean or summer mean precipitation over the entire time period ( $n$ indicates the number of simulations per case, multiplying this number with the period length yields the number of data points on which each plot is based). A Gaussian Kernel smoother with a bandwidth of 15 days was used for plotting. 


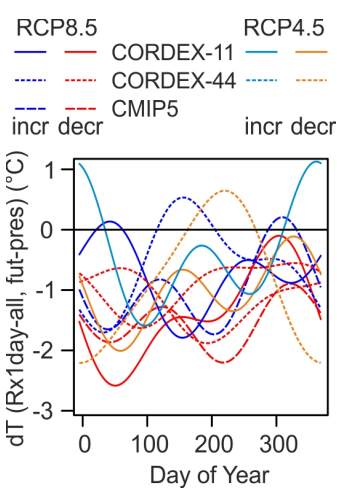

Fig. S5: Temperature difference as a function of calendar day between event days (Rx1day) and all days, expressed as difference between the future (2065-2099) and the present (1971-2005). The plot is the same as in Fig. 3 (top right), but with the simulations stratified into those with increasing or 42 decreasing summer precipitation (only multi-model ensembles; ENSEMBLES is not shown as all members show decreased summer precipitation).

44

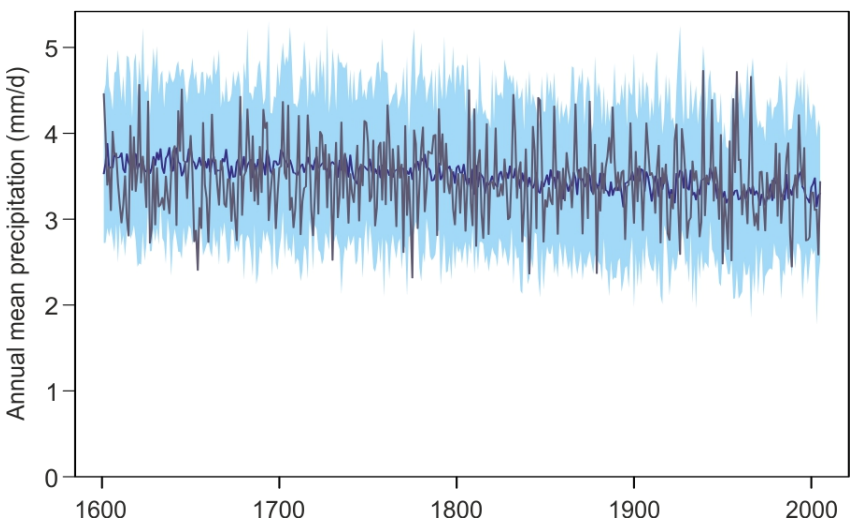

Fig. S6: Annual mean precipitation in CCC400. Solid blue line and shading indicate ensemble mean and range, the grayish line shows the run with corrected land-surface. 